\title{
Attitudes of Consumers from Educons University toward Advertising through Sport among the Frequency of Watching Sports Events
}

\author{
Dusan Stupar' , Jovan Gardasevic'², Bojan Masanovic ${ }^{2}$ \\ 'Educons University, Faculty of Sport and Tourism, Novi Sad, Serbia, ${ }^{2}$ University of Montenegro, Faculty for Sport and Physical Education, Niksic, \\ Montenegro
}

\begin{abstract}
This investigation was aimed at gaining relevant knowledge about the attitudes of Educons University consumers toward advertising through sport among. The sample included 200 students from Faculty of sport and tourism in Novi Sad, divided into six subsample groups: consumers, who do not watch sports events at all, then consumers who watch sports events 1-30 minutes, next 31-60 minutes, 61-90 minutes, 91-120 minutes, as well as consumers who watch sports events more than 120 minutes during the typical day. The sample of variables contained the system of three general attitudes which were modelled by seven-point Likert scale. The results of the measuring were analyzed by multivariate analysis (MANOVA) and univariate analysis (ANOVA) and Post Hoc test. Based on the statistical analyses it was found that significant differences occur at multivariate level, as well as between all three variables at a significance level of $p=.00$. Hence, it is interesting to highlight that it was found there are significant differences showed up between the attitudes of consumers toward advertising through sport among the frequency of watching sports events. The significant differences were found in two of three variables, while the consumers who do not watch sports events had much more negative attitudes toward advertising though sport.
\end{abstract}

Key words: Attitudes, Advertising, Sports Events, Novi Sad

\section{Uvod}

Zaključci pionirskih studija iz navedene oblasti koji su objavljeni od strane Bauer-a i Greiser-a (Popović, 2011) i Lutz-a (Klačar i Popović, 2010) pokrenuli su ideje koje se odnose na činjenicu da stavovi potrošača prema reklmairanju predstavljaju jedan od značajnih faktora koji mogu ojačati efikasnost reklamnih kampanja, uglavnom zbog razloga da kognitivna sposobnost potrošača prema reklamiranju jeste sadržana u njihovim osjećanjima i mislima (Muratović, Bjelica, \& Popović, 2014). Ako se nastavi sa istraživanjem ovog pitanja i ode se mnogo dublje, zanimljivo je da se primjećuje postojanje brojnih studija koje su istraživali stavove potrošača prema reklamiranju, ali većina njih smatra stavove potrošača prema reklamiranju samo uopšteno (Bjelica i Popović, 2011; Popo- vić, 2011b; Popović, Molnar, i Radovanović, 2011a; Popović, Matić, Milašinović, Jakšić, \& Bjelica, 2015a; Popović, Matić, Milašinović, Hadžic, Milošević, i Bjelica, 2015b; Popović, Matić, Milašinović, Vujović, Milošević, i Bjelica, 2015c). U svakom slučaju, neki od njih su zaključili da su stavovi prema reklamiranju pokazali negativan trend tokom 1960-ih i 1970ih (Popović, Bjelica, Jakšić, \& Georgiev, 2013; Popović, 2015; Popović \& Milašinović, 2016), dok su drugi pronašli povoljnije stavove ispitanika $\mathrm{u}$ istom periodu (Popović, 2011). Ove nedosljednosti su navele na sumnju da reklamne kampanje koje koriste elemente iz specificnih medijuma utiču na stavove potrošača prema reklamiranju u skladu sa tim (Popović, 2011). Neki autori su vjerovali da je jedan od najrelevantnijih medija, upravo sport, odnosno sportisti i njihovi timovi,

Correspondence:

Montenegro B. Masanovic

Gport University of Montenegro, Faculty for Sport and Physical Education, Narodne omladine bb, Niksic, Montenegro E-mail: bojanma@ac.me 
sportski događaji i sportski objekti (Bjelica i Popović, 2011), uglavnom iz razloga sto ovi elementi mogu da utiču na stavove potrošača i naprave značajne oscilacije kod stavova u poređenju sa ostalim elementima (Bjelica, Popović, Jakšić, Hadžic, \& Akpinar, 2014b; Bjelica i Popović, 2015a; Bjelica \& Popović, 2015b; Bjelica, Gardašević, Vasiljević, \& Popović, 2016a; Bjelica, Gardašević, Vasiljević, \&Popović, 2016c; Zorić, Mašanović, \& Gardašević, 2017; Gardašević, Zorić, \& Mašanović, 2017; Mašanović, Zorić, \& Gardašević, 2018; Gardašević, Zorić, \& Mašanović, 2018; Bajramović, Zorić, \& Mašanović, 2018; Gardašević, Bajramović, \& Mašanović, 2018; Zorić, Gardašević, \& Bajramović, 2018). Iz tog razloga, mnogi istraživaci priznaju sport kao nezavisnu reklamnu platformu koju poslovni subjekti mogu koristiti kako bi prevazisli negativne stavove potrošača prema reklamiranju. Samim tim se postavilo i pitanje, kako posmatranje sportskih događaja utiče na stavove potrošača prema reklamiranju u sportu kao jedan od niza problema sa kojim se nije susrijetalo mnogo autora do sada (Bjelica, Popović, \& Akpinar, 2014a; Bjelica, Popović, \& Akpinar, 2015c; Bjelica, Popović, \& Akpinar, 2016b; Bjelica, Popović, \& Akpinar, 2017; Mašanović, Zorić, \& Gardašević, 2017; Zorić, Mašanović, \& Gardašević, 2018; Bjelica, Gardašević, \& Ćorluka, 2018; Ćorluka, Bjelica, \& Vukotić, 2018; Vukotić, Ćorluka, \& Mašanović, 2018; Milovic, Corluka, \& Masanovic, 2018; Djurisic, Perovic, \& Masanovic, 2018; Kovacevic, Milosevic, \& Masanovic, 2018), a to upravo i jeste cilj ove studije.

\section{Metod}

Populaciju u ovoj studiji su činili studenti Fakulteta za sport i turizam u Novom Sadu koji su u vrijeme anketiranja, imali boravište na teritoriji Srbije, dok je uzorak ispitanika organizovan putem kombinovanja ili raslojavanja, tako da su obrađena različita svojstva navedene populacije i različiti prostori na kojima je ona egzistirala.

Upitnici su distribuirani studentima osnovnih studija $\mathrm{u}$ štampanom i elektronskom obliku. Ukupno je prikupljeno 211 upitnika, ali je 11 upitnika bilo isključeno iz analize, budući da nisu bili adekvatno popunjeni, tako da je u istraživanju učestvovalo, ukupno 200 ispitanika (slučajno odabranih studenta Fakulteta za sport i turizam u Novom Sadu). Instrument istraživanja je predstavljao standardizovani upitnik (Popović, 2011) i sastojao se iz dva dijela, generalnih stavova prema reklamiranju u sportu i socio-demografskih karakteristika ispi- tanika kada je učestalost posmatranja sportskih događaja tokom dana u pitanju. Sistem promjenljivih u ovom upitniku je sadržao tri tvrdnje koje su ispitanici trebali da ocijene prema sedmo-stepenoj Likertovoj skali vrijednosti, kao i šest sociodemografskih karakteristika ispitanika (uopšte ne posmatraju, 1-30 minuta, 31-60 minuta, 61-90 minuta, 91-120 minuta, i više od 120 minuta). Popunjavanje upitnika nije trajalo, u prosjeku vise od 10 minuta a ispitanici su u anketi učestvovali na dobrovoljnoj osnovi. Važno je naglasiti da je anketa bila anonimna i da su svi odgovori bili strogo povjerljivi. Vrijedno je napomenuti i da su ispitanici, i pored svega navedenog imali mogucnost da u svakom momentu opozovu svoje učešće u anketi, ali se niko od njih nije na tako nesto odlucio.

Empirijski podaci su analizirani putem statističkog paketa za drustvene nauke (SPSS 20.0), a kao prvi korak, bila je primijenjena deskriptivna statistika kojom su izračunati, prije svega frekvencija, zatim aritmeticka sredina, standardna devijacija, kao i mjere asimetrije (Skewness) i spljoštenosti (Kurtosis) za svaku od tvrdnji. Budući da su se promjenljive u ovoj studiji nalazile na neparametrijskim skalama, radi detaljnijih analiza koje su slijedile, bilo je neophodno da se one, primjenom Blomovog postupka transformišu u skale višeg reda. Zatim su primjenom multivarijatne analize varijanse (MANOVA), univarijatne analize varijanse (ANOVA) i LSD Post Hoc testa, utvrđene razlike u generalnim stavovima ispitanika prema reklamiranju u sportu u odnosu na učestalost posmatranja sportskih događaja tokom dana.

\section{Rezultati}

U prvoj tabeli su prikazani deskriptivni statistički podaci za sve tri tvrdnje koje su se odnosile na generalne stavove ispitanika prema reklamiranju u sportu. Prije svega, prikazana je aritmetička sredina koja oslikava pozitivne vrijednosti stavova kada su sve tri tvrdnje u pitanju, dok vrijednosti standardne devijacije pokazuju da elementi skupa, u prosjeku ne odstupaju značajno od aritmeticke sredine. Kada se govori o mjerama asimetrije (Skewness) i spljoštenosti (Kurtosis), negativne vrijednosti asimetrije kod svih promjenljivih pokazuju da je većina rezultata desno od srednje vrijednosti, među većim vrijednostima, dok negativne vrijednosti spljoštenosti kod sve tri promjenljive (GSS1, GSS2 i GSS3) pokazuju da je raspodjela šiljatija od normale tj. da ima više rezultata nagomilanih oko centra raspodjele.

Tabela 1. Generalni stavovi prema reklamiranju u sportu

\begin{tabular}{ccccccc}
\hline & \multirow{2}{*}{ Mean } & \multirow{2}{*}{ S.D. } & \multicolumn{2}{c}{ Skewness } & \multicolumn{2}{c}{ Kurtosis } \\
\cline { 4 - 7 } & & & Statistic & S.E. & Statistic & S.E. \\
\hline GSS1 & 4.65 & 1.640 & -.259 & .172 & -.571 & .342 \\
GSS2 & 5.01 & 1.535 & -.379 & .172 & -.535 & .342 \\
GSS3 & 4.41 & 1.450 & -.184 & .172 & -.159 & .342 \\
\hline
\end{tabular}

Legenda: Mean - Aritmetička sredina; S.D. - Standardna devijacija; Skewness - Mjera asimetrije; Kurtosis Mjera spljoštenosti; Statistic - Statistička vrijednost; S.E. - Standardna greška; GSS1 - Moje opšte mišljenje je naklonjeno reklamiranju u sportu; GSS2 - Sveobuhvatno. smatram da je reklamiranje u sportu dobra stvar; GSS3 - Sveobuhvatno. da li ne volite ili volite reklamiranje u sportu

U nastavku ove studije su prikazani komparativni statistički podaci generalnih stavova prema reklamiranju u sportu koji su dobijeni primjenom multivarijatne analize varijanse (MANOVA), univarijatne analize varijanse (ANOVA) i LSD Post Hoc testa, a u cilju utvrđivanja razlike u generalnim stavovima ispitanika prema reklamiranju u sportu u odnosu na učestalost posmatranja sportskih događaja tokom dana.
Inspekcijom druge tabele u kojoj su prikazani rezultati multivarijatne analize, jasno se uočava da u cijelom sistemu upoređivanih parametara postoji statistički značajna razlika u generalnim stavovima prema reklamiranju u sportu u odnosu na učestalost posmatranja sportskih događaja tokom dana $(\mathrm{p}=.024)$. 
Tabela 2. Multivarijatna značajnost razlika u sistemu generalnih stavova prema reklamiranju u sportu kod ispitanika sa različitim navikama kada je posmatranja sportskih događaja u pitanju

\begin{tabular}{ccccc}
\hline & & N & Mean & S.D. \\
\hline GSS1 & Ne posmatraju & 15 & 4.53 & 1.060 \\
& $1-30$ & 53 & 4.92 & 1.796 \\
& $31-60$ & 48 & 4.25 & 1.682 \\
& $61-90$ & 23 & 4.74 & 1.711 \\
& $91-120$ & 19 & 5.05 & 1.393 \\
& $>120$ & 42 & 4.57 & 1.595 \\
& Ukupno & 200 & 4.65 & 1.640 \\
\hline GSS2 & Nesmatraju & 15 & 5.27 & 1.387 \\
& $1-30$ & 53 & 5.36 & 1.688 \\
& $31-60$ & 48 & 4.46 & 1.501 \\
& $61-90$ & 23 & 5.22 & 1.476 \\
& $91-120$ & 19 & 5.42 & 1.170 \\
& $>120$ & 42 & 4.83 & 1.464 \\
& Ukupno & 200 & 5.01 & 1.535 \\
\hline GSS3 & $1-30$ & 15 & 4.20 & 1.014 \\
& Nesmatraju & 53 & 4.45 & 1.612 \\
& $31-60$ & 48 & 4.00 & 1.429 \\
& $61-90$ & 23 & 5.30 & 1.363 \\
& $91-120$ & 19 & 4.58 & 1.539 \\
& $>120$ & 42 & 4.36 & 1.226 \\
& Ukupno & 200 & 4.41 & 1.450 \\
\hline
\end{tabular}

$F=1.865 ; p=.024$

Inspekcijom treće tabele u kojoj su prikazani rezultati univarijatne analize, jasno se uočava da je, takođe došlo do statistički značajnih razlika u generalnim stavovima prema rekla- miranju u sportu u odnosu na posmatranje sportskih događaja kod dvije promjenljive (GSS2 i GSS3), dok kod treće varijable (GSS1) navedena diskriminacija nije utvrđena.

Tabela 3. Univarijatna značajnost razlika u sistemu generalnih stavova prema reklamiranju u sportu kod ispitanika sa različitim navikama kada je posmatranje sportskih događaja u pitanju

\begin{tabular}{lcc}
\hline & F & p \\
\hline GSS1 & 1.149 & .336 \\
GSS2 & 2.421 & .037 \\
GSS3 & 2.769 & .019 \\
\hline
\end{tabular}

Inspekcijom naredne tri tabele gdje su prikazani rezultati Post Hoc testa koji ukazuju na značajnost razlika između parova pojedinačnih entiteta sa različitim navikama kada je posmatranje sportskih događaja u pitanju za svaku promjen- ljivu, po rezultatima koji su se pojavili na univarijatnom nivou, očekivano uočavamo statistički značajne razlike pojedinih parametara kod sve tri promjenljive.

Tabela 4. Utvrđivanje značajnih razlika u sistemu generalnih stavova prema reklamiranju u sportu primjenom Post Hoc testa između pojedinačnih entiteta sa različitim navikama kada je posmatranje sportskih događaja u pitanju kod tvrdnje „moje opšte mišljenje je naklonjeno reklamiranju u sportu"

\begin{tabular}{cccccc}
\hline vs & Ne posmatraju & $\mathbf{1 - 3 0}$ & $\mathbf{3 1 - 6 0}$ & $\mathbf{6 1 - 9 0}$ & $\mathbf{9 1 - 1 2 0}$ \\
\hline $1-30$ & .415 & & & & \\
$31-60$ & .559 & .040 & & & \\
$61-90$ & .705 & .651 & .240 & & \\
$91-120$ & .360 & .770 & .072 & .538 & \\
$>120$ & .938 & .298 & .354 & .693 & .289 \\
\hline
\end{tabular}

Došlo se do zaključka da se kod prve tvrdnje „moje opšte mišljenje je naklonjeno reklamiranju u sportu“ javljaju razlike između ispitanika koji posmatraju sportske događaje 1-30 minuta dnevno i ispitanika koji posmatraju sportske događaje 31-60 mi- nuta dnevno. Možemo uočiti da pripadnici grupe koje posmatra sportske događaje 91-120 minuta dnevno imaju najviše pozitivnih odgovora, dok najmanje pozitivnih rezultata vidimo kod grupe koje sportske događaje posmatra 31-60 minuta dnevno. 
Tabela 5. Utvrđivanje značajnih razlika u sistemu generalnih stavova prema reklamiranju u sportu primjenom Post Hoc testa između pojedinačnih entiteta sa različitim navikama kada je posmatranje sportskih događaja u pitanju kod tvrdnje „sveobuhvatno, smatram da je reklamiranje u sportu dobra stvar"

\begin{tabular}{cccccc}
\hline vs & Ne posmatraju & $\mathbf{1 - 3 0}$ & $\mathbf{3 1 - 6 0}$ & $\mathbf{6 1 - 9 0}$ & $\mathbf{9 1 - 1 2 0}$ \\
\hline $1-30$ & .835 & & & & \\
$31-60$ & .072 & .003 & & & \\
$61-90$ & .922 & .708 & .049 & & \\
$91-120$ & .767 & .877 & .020 & .664 & \\
$>120$ & .341 & .094 & .241 & .328 & .160 \\
\hline
\end{tabular}

Došlo se do zaključka da se kod druge tvrdnje „sveobuhvatno, smatram da je reklamiranje u sportu dobra stvar" javljaju razlike između ispitanika koji posmatraju sportske događaje 31-60 minuta dnevno i većine ostalih entiteta. Možemo uočiti da pripadnici grupe koje posmatra sportske događaje 91-120 minuta dnevno imaju najviše pozitivnih odgovora, dok najmanje pozitivnih rezultata vidimo kod grupe koje sportske događaje posmatra 31-60 minuta dnevno.

Tabela 6. Utvrđivanje značajnih razlika u sistemu generalnih stavova prema reklamiranju u sportu primjenom Post Hoc testa između pojedinačnih entiteta sa različitim navikama kada je posmatranje sportskih događaja u pitanju kod tvrdnje „sveobuhvatno, da li ne volite ili volite reklamiranje u sportu"

\begin{tabular}{cccccc}
\hline vs & Ne posmatraju & $\mathbf{1 - 3 0}$ & $\mathbf{3 1 - 6 0}$ & $\mathbf{6 1 - 9 0}$ & $\mathbf{9 1 - 1 2 0}$ \\
\hline $1-30$ & .543 & & & & \\
$31-60$ & .634 & .111 & & & \\
$61-90$ & .020 & .017 & .000 & & \\
$91-120$ & .440 & .740 & .134 & .101 & \\
$>120$ & .713 & .744 & .235 & .011 & .573 \\
\hline
\end{tabular}

Došlo se do zaključka da se kod treće tvrdnje „sveobuhvatno, da li ne volite ili volite reklamiranje u sportu“ pojavljuju razlike između ispitanika koji posmatraju sportske događaje 61-90 minuta dnevno i većine ostalih entiteta. Možemo uočiti da pripadnici grupe koje posmatra sportske događaje 61-90 minuta dnevno imaju najviše pozitivnih odgovora, dok najmanje pozitivnih rezultata vidimo kod grupe koja sportske događaje posmatra 31-60 minuta dnevno.

\section{Diskusija}

S obzirom da su rezultati pokazali da ispitanici imaju veoma pozitivan stav prema reklamiranju u sportu što potvrđuje visoka vrijednost aritmetičke sredine za sve tri promjenljive, kao i da skoro dvije trećine ispitanika imaju pozitivan stav prema reklamiranju u sportu što se ogleda u izrazito negativnim vrijednostima mjera asimetrije, trebalo bi naglasiti da su ovi rezultate usaglašeni sa rezultatima prethodnih istraživanja (Bjelica, i Popović, 2011; Popović, 2011b; Popović, Molnar, i Radovanović, 2011a; Popović, Matić, Milašinović, Jakšić, \& Bjelica, 2015a; Popović, Matić, Milašinović, Hadžić, Milošević, \& Bjelica, 2015b; Popović, Matić, Milašinović, Vujović, Milošević, \& Bjelica, 2015c), i da ne postoje značajne razlike koje bi trebalo pomenuti. Dobijeni rezultati, takođe jasno ukazuju da ispitanici koji žive na različitim lokacijama, kao što su Sjedinjene države, Turska, Crna Gora, Srbija i Bosna i Hercegovina, imaju pozitivne stavove prema reklamiranju u sportu, dok je, ipak, poređenja radi, vrijedno navesti da prema Mittal-u (1994), različite studije ukazuju na negativne stavove kada je reklamiranje proizvoda $\mathrm{u}$ tradicionalnim industrijama $\mathrm{u}$ pitanju. Prema tome, više je nego evidentno da je primjena sporta u savremenoj poslovnoj komunikaciji uticala da se generalni stavovi potrošača značajno promijene kada je reklamiranje u pitanju, a prepoznavanje privlačnosti sporta je omogućilo poslovnim organizacijama da se približe sportskim potroša- čima i na mnogo bezbolniji način utiču na njihovo ponašanje. Utvrđivanjem razlike $u$ generalnim stavovima ispitanika prema reklamiranju u sportu u odnosu na posmatranje sportskih događaja tokom dana, u ovoj studiji su pronađene razlike u stavovima između ispitanika koji imaju različite navike kada je posmatranje sportskih događaja tokom dana u pitanju. Ove razlike su se pojavile kod dvije od tri promjenljive na univarijatnom nivou. Kod sve tri promjenljive „moje opšte mišljenje je naklonjeno reklamiranju u sportu“, „sveobuhvatno, smatram da je reklamiranje u sportu dobra stvar" $i$,sveobuhvatno, da li ne volite ili volite reklamiranje u sportu“, uočava se najmanje pozitivnih rezultata kod entiteta koji posmatra sportske događaje 31-60 minuta dnevno. Takođe se uočava mnogo pozitivnih rezultata kod onih grupa koje posmatraju sportske događaje 61-90 i 91-120 minuta dnevno.

Interesantno je istaći da su pronađene značajne razlike između potrošača koji posmatraju sportske aktivnosti u različitim vremenskim intervalima, što je bio slučaj u prethodnim studijama (Molnar, Lilić, Popović, Akpinar, \& Jakšić, 2011; Popović, Jakšić, Matić, Bjelica, \& Maksimović, 2014; Popović, Bjelica, Georgiev, \& Akpinar, 2011b; Popović, Matić, Milašinović, Jakšić, \& Bjelica, 2015d; Popović, Matić, Milašinović, Hadžić, Milošević, \& Bjelica, 2015e; Popović, Matić, Milašinović, Vujović, Milošević, \& Bjelica, 2015f; Popović, Jakšić, Matić, Bjelica, \& Maksimović, 2015g). Ovi rezultati su veoma važni za poslovne subjekte u Srbiji ali i za naučnu javnost, uglavnom iz razloga što ne mogu spojiti sve potencijalne potrošače koji posmatraju sportske aktivnosti u različinim vremenskim intervalima u jednu homogenu grupu, što se slaže sa prethodnim istraživanjima (Bjelica, Popović, Jakšić, Hadžić, \& Akpinar, 2014b; Bjelica, \& Popović, 2015a; Bjelica, \& Popović, 2015b; Bjelica, Gardasevic, Vasiljevic, \& Popovic, 2016a; Bjelica, Gardašević, Vasiljević, \& Popović, 2016c). 


\section{Acknowledgements}

There are no acknowledgements.

\section{Conflict of Interest}

The authors declare that there are no conflict of interest.

Received: 29 March 2018| Accepted: 28 April 2018| Published: 13 July 2018

\section{References}

Bajramović, I., Zorić, G., \& Mašanović, B. (2018). Attitudes of Consumers from the Sarajevo Canton in Bosnia and Herzegovina toward Advertising through Sport among the Frequency of Watching Sports Events. Journal of Anthropology of Sport and Physical Education, 2(2), 43-7.

Bjelica, D., \& Popović, S. (2015a). Evolucija reklamiranja sa posebnim osvrtom na reklamiranje u sportu. Sport Mont, 13(43,44,45), 35-41.

Bjelica, D., \& Popović, S. (2015b). Evolution of Advertising with a Specific Retrospection at Sport Advertising. In Book of Abstracts of the 12th International Scientific Conference on Transformation Process in Sport "Sport Performance" (60-61), Podgorica: Montenegrin Sports Academy.

Bjelica, D., Gardašević, J., \& Corluka, M. (2018). Attitudes of Consumers from the Mostrar Canton in Bosnia and Herzegovina toward Advertising through Sport among the Question how often Consumers purchase Sporting Goods. Journal of Anthropology of Sport and Physical Education, 2(2), 3-7.

Bjelica, D., Gardašević, J., Vasiljević, I., \& Popović, S. (2016a). Ethical Dilemmas of Sport Advertising. Sport Mont, 14(3), 41-3.

Bjelica, D., Gardašević, J., Vasiljević, I., \& Popović, S. (2016c). Ethical dilemmas of sport advertising. In Book of Abstracts of the 13th International Scien tific Conference on Transformation Process in Sport "Sport Performance" (41), Podgorica: Montenegrin Sports Academy.

Bjelica, D., i Popović, S. (2011). Stavovi potrošača prema reklamiranju u sportu u odnosu na učestalost posmatranja sportskih događaja. Sportske nauke izdravlje, 1(2), 114-9.

Bjelica, D., Popović, S., \& Akpinar, S. (2014a). Book of Abstracts of the 11th International Scientific Conference on Transformation Process in Sport "Sport Performance". Podgorica: Montenegrin Sports Academy.

Bjelica, D., Popović, S., \& Akpinar, S. (2015c). Book of Abstracts of the 12th International Scientific Conference on Transformation Process in Sport "Sport Performance". Podgorica: Montenegrin Sports Academy.

Bjelica, D., Popović, S., \& Akpinar, S. (2016b). Book of Abstracts of the 13th International Scientific Conference on Transformation Process in Sport "Sport Performance". Podgorica: Montenegrin Sports Academy.

Bjelica, D., Popović, S., \& Akpinar, S. (2017). Book of Abstracts of the 14th International Scientific Conference on Transformation Process in Sport "Spor Performance". Podgorica: Montenegrin Sports Academy.

Bjelica, D., Popović, S., Jakšić, D., Hadžić, R., \& Akpinar, S. (2014b). How Does Advertising through Sport Work? Evidence from Turkey. In Proceeding book of the 7th International Scientific Conference on Kinesiology "Fundamental and Applied Kinesiology - Steps Forward" (477). Opatija: University of Zegreb, Faculty of Kinesiology.

Corluka, M., Bjelica, D., \& Vukotić, M. (2018). Attitudes of Consumers from the Mostar Canton in Bosnia and Herzegovina toward Advertising through Sport among the Question how Often they Participate in Sports Activities. Journal of Anthropology of Sport and Physical Education, 2(2), 9-13.

Djurisic, V., Perovic, D., \& Masanovic, B. (2018). Attitudes of consumers from Podgorica toward advertising through sport among the question how often consumers purchase sporting goods. Journal of Anthropology of Sport and Physical Education, 2(2), 55-60. doi: 10.26773/jaspe. 180410

Gardašević, J., Bajramović, I., \& Mašanović, B. (2018). Attitudes of Consumers from the Sarajevo Canton in Bosnia and Herzegovina toward Advertising through Sport among the Question how Often they Participate in Sports Activities. Journal of Anthropology of Sport and Physical Education, 2(2), 37-41

Gardašević, J., Zorić, G., \& Mašanović, B. (2017). Attitudes of Turkish consumers toward advertising through sport among the question how often they participate in sports activities. Journal of Anthropology of Sport and Physical Education, 1(1), 23-7.

Gardašević, J., Zorić, G., \& Mašanović, B. (2018). Attitudes of Montenegrin consumers toward advertising through sport among the question how often they participate in sports activities. Journal of Anthropology of Sport and Physical Education, 2(1), 15-9.

Klačar, M., i Popović, S. (2010). Reklamiranje u sportu kao efektivno sredstvo savremene komunikacije. Teme, 4, 1219-30.

Kovacevic, D., Milosevic, Z., \& Masanovic, B. (2018). Attitudes of consumers from Podgorica toward advertising through sport among the question how often they participate in sports activities. Journal of Anthropology of Sport and Physical Education, 2(2), 61-5. doi: 10.26773/jaspe.180411

Mašanović, B., Zorić, G., \& Gardašević, J. (2017). Attitudes of Turkish con- sumers toward advertising through sport among the frequency of watching sports events. Journal of Anthropology of Sport and Physical Education, 1(1), 3-7.

Mašanović, B., Zorić, G., \& Gardašević, J. (2018). Attitudes of Montenegrin consumers toward advertising through sport among the frequency of watching sports events. Journal of Anthropology of Sport and Physical Education, 2(1), 9-13.

Milovic, N., Corluka, M., \& Masanovic, B. (2018). Attitudes of consumers from Podgorica toward advertising through sport among the frequency of watching sports events. Journal of Anthropology of Sport and Physical Education, 2(2), 71-6. doi: 10.26773/jaspe.180413

Molnar, S., Lilić, Lj., Popović, S., Akpinar, S., \& Jakšić, D. (2011). Attitudes of various demographic groups toward advertising through sport at METU. Facta Universitatis, Series: Physical Education and Sport, 9(3), 255-63.

Muratović, A., Bjelica, D., \& Popović, S. (2014). Examining beliefs and attitudes toward advertising through sport among montenegrin consumers. Facta Universitatis, Series: Physical Education and Sport, 12(2), 95-104.

Popovic, S. (2011). Reklamiranje u sportu kao efektivno sredstvo savremene poslovne komunikacije. Neobjavljena doktoska disertacija, Novi Sad: Univerzitet u Novom Sadu.

Popović, S. \& Milašinović, R. (2016). Model of Advertising Communication in Sport. Sport Mont, 14(1), 33-8.

Popović, S. (2011b). Stavovi potrošača prema reklamiranju u sportu u odnosu na učestalost kupovine sportskih proizvoda. Sport Mont, 9(28,29,30), $140-7$.

Popović, S. (2015). Sport Nowadays (In Montenegrin). In D. Bjelica (Ed.) Advertising Role of Sponsorship in Modern Sport (pp. 111-116). Podgorica: Montenegrin Sports Academy.

Popović, S., Bjelica, D., Georgiev, G., \& Akpinar, S. (2011b). Comparison of attitudes toward advertising through sport between Montenegrin and Turkish stakeholders. In Proceedings book of the 6th International Scientific Conference on Kinesiology "Integrative Power of Kinesiology" (612). Opatija: University of Zegreb, Faculty of Kinesiology.

Popović, S., Bjelica, D., Jakšić, D, \& Georgiev, G. (2013). How does Advertising Through Sport Work? Evidence from Montenegro. In Book of Abstracts of the $18^{\text {th }}$ Annual Congress of the European College of Sport Science (444-445), Barcelona: National Institute of Physical Education of Catalonia.

Popović, S., Jakšić, D., Matić, R., Bjelica, D., \& Maksimović, N. (2014). Examining Beliefs and Attitudes toward Advertising through Sport among Serbian Consumers. In Book of abstracts of International conference "Economics and Management of Sports 2014" (pp. 11-12). Brno: Faculty of Sports Studies.

Popović, S., Jakšić, D., Matić, R., Bjelica, D., \& Maksimović, N. (2015g). Examining Beliefs and Attitudes toward Advertising through Sport among Serbian Consumers. Studia Sportiva, 9(1), 225-31.

Popović, S., Matić, R., Milašinović, R., Hadžić, R., Milošević, Z. \& Bjelica, D. (2015b). Stavovi srbijanskih potrošača prema reklamiranju u sportu u odnosu na učestalost kupovine sportskih proizvoda. Sport Mont, 13(43,44,45), 262-9.

Popović, S., Matić, R., Milašinović, R., Hadžić, R., Milošević, Z., \& Bjelica, D. (2015e). Attitudes of Serbian Consumers toward Advertising through Sport among the Question How Often Consumers Purchase Sporting Goods. In Book of Abstracts of the 12th International Scientific Conference on Transformation Process in Sport "Sport Performance" (59-60), Podgorica: Montenegrin Sports Academy.

Popović, S., Matić, R., Milašinović, R., Jakšić, D., \& Bjelica, D. (2015d). Attitudes of Serbian Consumers toward Advertising through Sport among the Question How Often They Participate in Sports Activities. In Book of Abstracts of the 12th International Scientific Conference on Transformation Process in Sport "Sport Performance" (58-9), Podgorica: Montenegrin Sports Academy.

Popović, S., Matić, R., Milašinović, R., Jakšić, D., \&Bjelica, D. (2015a). Stavovi srbijanskih potrošača prema reklamiranju u sportu u odnosu na učestalost bavljenja sportskim aktivnostima. Sport Mont, 13(43,44,45), 50-6.

Popović, S., Matić, R., Milašinović, R., Vujović, D., Milošević, Z. \& Bjelica, D. (2015c). Stavovi srbijanskih potrošača prema reklamiranju u sportu u odnosu na učestalost posmatranja sportskih događaja. Sport Mont, 13(43,44,45), 270-6.

Popović, S., Matić, R., Milašinović, R., Vujović, D., Milošević, Z., \& Bjelica, D. (2015f). Attitudes of Serbian Consumers toward Advertising through Sport among the Frequency of Watching Sports Events. In Book of Abstracts of the 12th International Scientific Conference on Transformation Process in Sport "Sport Performance" (60), Podgorica: Montenegrin Sports Academy.

Popović, S., Molnar, S., i Radovanović, D. (2011a). Stavovi potrošača prema reklamiranju u sportu u odnosu na učestalost bavljenja sportskim aktivnostima. Sport Mont, 9(28,29,30), 148-55. 
Vukotić, M., Corluka, M., \& Mašanović, B. (2018). Attitudes of Consumers from the Mostar Canton in Bosnia and Herzegovina toward Advertising through Sport among the Frequency of Watching Sports Events. Journal of Anthropology of Sport and Physical Education, 2(2), 19-23.

Zorić, G., Gardašević, J., \& Bajramović, I. (2018). Attitudes of Consumers from the Sarajevo Canton in Bosnia and Herzegovina toward Advertising through Sport among the Question how often Consumers purchase Sporting Goods. Journal of Anthropology of Sport and Physical Education, 2(2), 25-9.
Zorić, G., Mašanović, B., \& Gardašević, J. (2017). Attitudes of Turskish consumers toward advertising through sport among the question how often consumers purchase sporting goods. Journal of Anthropology of Sport and Physical Education, 1(1), 17-21. doi: 10.26773/jaspe.171003

Zorić, G., Mašanović, B., \& Gardašević, J. (2018). Attitudes of Montenegrin consumers toward advertising through sport among the question how often consumers purchase sporting goods. Journal of Anthropology of Sport and Physical Education, 2(1), 21-5. 